\title{
A Constituição do Campo da Educaçáo Especial Expressa na Revista Brasileira de EduCaÇão EspeCial - Rbee (1992-2017) ${ }^{1}$ THE CONSTITUTION OF THE FIELD OF SPECIAL EDUCATION EXPRESSED IN THE BRAZILIAN JOURNAL OF SPECIAL EDUCATION - RBEE (1992-2017)
}

\author{
José Geraldo Silveira BUENO3 \\ Sirleine Brandão de SOUZA ${ }^{4}$
}

\begin{abstract}
RESUMO: O objetivo do presente artigo é apresentar, analisar e discutir a constituição do campo da Educação Especial, tendo como fonte os textos publicados pelo periódico Revista Brasileira de Educaçáo Especial-RBEE, no período de 1992 até 2017 . Por meio da fonte selecionada, foi possível elaborar balanço tendencial referente aos sujeitos que produzem os discursos disseminados pelo periódico, bem como os sujeitos e as políticas que essas narrativas produzem e a forma pela qual sâo produzidas. Para tanto, foram selecionados, dentre o total de textos publicados, aqueles que apresentavam discussão ampla sobre a Educação Especial, por meio de três eixos de entrada: quem produziu esses artigos, o que produziram e por quais meios produziram essas narrativas. Os dados colhidos foram organizados por meio de indicadores que alimentaram o banco de dados, permitindo a elaboraçáo de tabelas e a análise das principais tendências dessa produção desde o seu lançamento até o ano de 2017, tendo como referencial teórico os estudos de Pierre Bourdieu, especificamente as noçóes de campo e linguagem. Destacam-se como resultados da análise a grande incidência de produçóes da regiâo Sudeste do Brasil, de autores com título de doutores inseridos no campo acadêmico vinculados à educaçáo, culminando com a análise dos termos que designam a população atendida pela Educação Especial e que expressam a disputa pela autoridade científica desse campo de investigação.
\end{abstract}

PALAVRAS-CHAVE: Educação Especial. Pesquisa educacional. Pesquisa bibliográfica. Produção acadêmica.

\begin{abstract}
The purpose of this paper is to present, analyze and discuss the constitution of the field of Special Education, having the texts published by the Brazilian Journal of Special Education - RBEE- from 1992 to 2017 as its source. Through this selected source, it was possible to elaborate a trend balance regarding the subjects that produce the discourses disseminated by the journal, as well as the subjects and policies that these narratives produce and the way in which they are produced. In order to do so, among the total of published texts, those which presented a broad discussion on Special Education were selected through three axes of entry: who produced the papers, what was produced and by what means these narratives were produced. The collected data were organized through indicators that fed the database allowing both the elaboration of tables and the analysis of the main trends of this production from its launch until the year 2017, having Pierre Bourdieu's studies as theoretical reference, specifically the notions of field and language. The highlighted results of this analysis are the high incidence of productions in the Southeastern region of Brazil, coming from authors with a doctorate degree in the academic field related to education, culminating with the analysis of terms that designate the population assisted by Special Education and that express the dispute over the scientific authority of this field of investigation.
\end{abstract}

KEYWORDS: Special Education. Educational research. Bibliographic research. Academic production.

\footnotetext{
${ }^{1}$ http://dx.doi.org/10.1590/S1413-65382418000400004

${ }^{2}$ Este artigo apresenta alguns resultados da tese de Doutorado Excepcionalidade, deficiência ou necessidades educacionais especiais: $O$ aluno como constituinte do campo da educação especial. Teve o apoio financeiro da CAPES e CNPq.

${ }^{3}$ Doutor em Educação. Professor da Faculdade de Educação e do Programa de Pós-Graduação em Educação - PEPG da Pontifícia Universidade Católica de São Paulo - PUC-SP, São Paulo - SP, Brasil. jotage@pucsp.br.

${ }^{4}$ Doutora em Educação pelo Programa de Pós-Graduação em Educação - PEPG da Pontifícia Universidade Católica de São Paulo, São Paulo - SP, Brasil. Membro do Projeto de Pesquisa: O estado da arte da produção acadêmica em Educação Especial no Brasil. sirleinesouza@uol.com.br.
} 


\section{INTRODUÇÃo}

Mediante a conceituação de campo científico efetuada por Pierre Bourdieu (1983) que, segundo ele, não é imposto e nem construído por meio de objetivos empíricos, antes, define-se por meio de relaçôes objetivas estabelecidas entre agentes que detêm determinados lugares e que lutam pela aquisição de certa legitimidade culminando na autoridade científica "definida, de maneira inseparável como capacidade técnica e poder social" (Bourdieu, 1983, p. 122), compreende-se a Educação Especial como campo de conhecimento, cujo lócus se situa no espaço social em relaçôes estabelecidas, objetiva e subjetivamente, com referência a outros campos, e que possui determinadas regularidades constituídas no e pelo próprio campo, decorrentes da dinâmica de forças específicas confrontadas entre si.

Segundo Bourdieu (2004), o campo científico está inserido no campo da produção cultural, assim como o campo artístico, literário, religioso, etc., com "seus dominantes e dominados, seus conservadores e sua vanguarda, suas lutas subversivas e seus mecanismos de reprodução [...]" (Bourdieu, 2004, p. 170), embora haja uma forma específica de organização e estruturação no interior, tanto deste quanto de outros campos. Assim, o campo científico é um espaço, um lugar de "luta concorrencial" (Bourdieu, 1983, p. 122), pela posse da autoridade científica, demandando tanto capacidade técnica, quanto poder social.

Nessa perspectiva, entende-se a linguagem como um instrumento de ação e de poder, muito mais do que um objeto de intelecção, na medida em que as trocas linguísticas no interior das relaçóes de comunicaçáo, que implicam conhecimento e reconhecimento, são também relaçóes de poder simbólico, atualizando a estrutura de força entre os agentes e o campo (Bourdieu, 1991). Assim, um discurso pode tornar-se hegemônico dadas as condiçóes de sua produção e dos lugares ocupados objetivamente pelos agentes e/ou instituiçôes em determinados campos sociais.

Assim, para analisarem-se a produção e a circulação do discurso acadêmico-científico, faz-se necessário considerar que ele se produz no interior de um campo, em contextos e mercados particulares e que "[...] as propriedades desses mercados portam produtos linguísticos de um determinado valor [...]" (Bourdieu, 1991, p. 32). Esses mercados linguísticos contribuem não somente para agregar valor simbólico e, portanto, poder simbólico às expressóes linguísticas, ou se preferir, a um discurso, mas também para lhes dar sentido.

Esse autor assinala que o conhecimento e o reconhecimento das leis intrínsecas do mercado e de suas sançóes determinam as estratégias do discurso a serem postas em jogo; assim sendo, os discursos são sempre orientados pela preocupação em cumprir os requisitos de determinado mercado, bem como portam o compromisso entre o que dizer e a censura imposta pelo campo ou mercado.

Dessa forma, no trabalho proposto, a análise considera o campo da Educação Especial, como campo de conhecimento dotado de forças que o movimentam e que tanto sua constituiçáo quanto do sujeito designado como seu público instituem-se na dinâmica contraditória da própria história e desenvolvimento social. Nessa perspectiva, compreender a dinâmica da Educação Especial como campo de conhecimento, em que são travadas disputas pelo reconhecimento da autoridade científica, exige que, além dos conteúdos intrínsecos propriamente 
ditos da produção acadêmica, se verifique que posições são ocupadas pelos agentes que as produzem, assim como "o que" e "por quais meios" esses agentes produzem as suas narrativas.

Dessa forma, o propósito deste artigo é apresentar, analisar e discutir - por meio dos dados recolhidos na Revista Brasileira de Educação Especial (RBEE), no período de 1992 a 2017, os seguintes indicadores: quem são os autores institucionais dessas narrativas; que sujeitos e políticas de Educação Especial essas narrativas produzem; de que forma são produzidas essas narrativas.

Partindo do princípio de que a relação entre o referencial teórico e o tratamento dado ao material empírico produz o objeto de pesquisa, cabe, no presente artigo, detalhar os procedimentos da investigação, que procura oferecer uma nova contribuição para as pesquisas bibliográficas que utilizaram a RBEE como fonte para, em seguida, apresentar os seus resultados.

\section{Método}

Conforme explicitado anteriormente, a fonte que serviu de base para este balanço tendencial foram os textos ${ }^{5}$ publicados na Revista Brasileira de Educação Especial (RBEE), no período de 1992 (ano da primeira publicação) a 2017. A opção pelo balanço da produção desse periódico justifica-se porque ele é o veículo especializado nacional mais reconhecido no campo da Educação Especial, congrega a contribuição de pesquisadores de todo o país e veicula trabalhos desde o início da década de 1990, o que permitiu a análise do movimento histórico da conceituação da população da Educação Especial. ${ }^{6}$

Cabe ressaltar, em primeiro lugar, que, coerentemente com a referência teórica utilizada, a saber, o conceito de campo científico como produção cultural com relativa autonomia (Bourdieu, 1983), nossa intenção não foi a de produzir um "estado da arte", mas selecionar artigos publicados na revista que fossem a expressão qualificada da abrangência da Educação Especial por meio da caracterização de seu alunado.

$\mathrm{Na}$ coleta de dados, constatou-se que o acesso online do acervo total da Revista exige a consulta de dois repositórios, pois, na Scientific Electronic Library Online (SciELO), contam somente os exemplares do volume 11, número 2 em diante. Já, para acessar os exemplares publicados no período anterior, foi necessário recorrer ao repositório constante da Associação Brasileira de Pesquisadores em Educação Especial (período de 1992 até 2005, Volume 1 ao Volume 11, Número 1).

O passo seguinte foi fazer o reconhecimento da estrutura do periódico, por meio do levantamento de todas as seçóes que compóem a Revista sobre as seguintes informações: ano de publicação, nome das seçóes, número de textos publicados em cada seção.

\footnotetext{
${ }^{5} \mathrm{Na}$ medida em que, neste artigo, estabelece-se distinção entre diferentes gêneros textuais (artigos, ensaios e relatos de pesquisa), utilizamos o vocábulo "texto" quando nos referimos genericamente a essas produçóes.

${ }^{6}$ No sistema de classificaçáo efetuado pela Coordenação de Aperfeiçoamento de Pessoal de Nível Superior (CAPES) - com vistas à avaliação da produção científica dos pesquisadores dos programas de Pós-Graduação no Brasil -, existem cinco periódicos científicos exclusivos de Educação Especial: dois periódicos classificados como A2, dois como B4 e um como C (editado em Portugal), sendo a RBEE um dos dois classificados como A2, sob a responsabilidade da Associação Brasileira de Pesquisadores em Educação Especial (ABPEE) e com indexação no SciELO.
} 
A partir dos dados obtidos, verificou-se que, de 1992 a 2017, somaram-se setecentos e um textos distribuídos por todas as seçóes da Revista, em vinte e três volumes e sessenta e um números, dentre os quais, para a realização deste balanço, optou-se por selecionar os ensaios, os relatos de pesquisa e os textos de 1992 a 2001, que naquele período estavam incluídos na seção "Artigos".

Para tanto, foram elaborados os seguintes critérios de seleção do corpus documental que compôs o acervo a ser examinado por esta investigação:

1. Abordar discussão abrangente sobre a Educação Especial.

2. Ser redigido em Língua Portuguesa e discorrer sobre assuntos que se refiram ao Brasil, mesmo que apresentem experiências compartilhadas com outros países.

3. Conter os seguintes descritores no corpo do texto: "EXCEPC" (excepcional, excepcionalidade); "DEFIC" (deficiente; deficiência); "NEE" (Necessidades educativas especiais; Necessidades educacionais especiais); "NE" (Necessidades especiais); "TRANST" (Transtorno). ${ }^{7}$

Para proceder à seleção dos textos, foi feita a leitura dos títulos de todos eles e verificada a abrangência da discussão. Nessa fase de busca, foi possível selecionar cento e cinquenta e oito textos, sendo 110 relatos de pesquisa e/ou relato de experiência, 23 ensaios e 5 artigos.

Após essa fase, passou-se para a busca, no texto, dos descritores anteriormente mencionados, com a finalidade de verificar se eles se adequavam aos critérios selecionados e se serviriam para a análise de acordo com o objetivo proposto para esta pesquisa. Essa fase de leitura e de busca possibilitou descartar os textos que, embora parecessem expressar em seu título discussóes abrangentes sobre Educação Especial, referiam-se a uma deficiência específica, ou que não serviriam para a discussão proposta na pesquisa - por se tratar de alguma experiência muito restrita ou porque não apresentavam no corpo do texto os descritores mencionados. Com esses procedimentos, 36 textos foram excluídos, o que redundou em corpus final composto por 122 textos, distribuídos entre 18 ensaios, 80 relatos de pesquisa ${ }^{8}$ e 24 artigos.

Após essa etapa, foi elaborada enquete no software Sphinx iQ29 com a finalidade de obter dados objetivos referentes aos textos selecionados e que compóem o próximo tópico deste texto. Tais dados referem-se aos seguintes elementos: Autor; Titulação; Ocupação; Campo de produção; Instituição; Programa e/ou Departamento; Região; Ano da publicação; Tema do texto; Descritor utilizado; Orientação metodológica; e Tipo de pesquisa.

Para preencher esses dados, recorreu-se, em primeiro lugar, ao próprio texto e às informaçóes disponíveis, e, em segundo lugar, ao currículo Lattes dos autores, uma vez que em muitos textos náo constavam informaçóes como: Funçáo, Titulação e Programa e/ou de-

\footnotetext{
${ }^{7}$ Cabe ressaltar que até o volume seis não foi possível proceder à averiguação por palavras-chave por meio do instrumento de busca, sendo necessário recorrer à leitura de todos os textos na íntegra. Acredita-se que a forma como o documento foi digitalizado não permitiu tal procedimento de busca.

${ }^{8}$ Aqui retirou-se o relato de experiência, dado que não foi selecionado de acordo com os critérios estabelecidos.

${ }^{9}$ O Sphinx iQ2 é um software de tratamento estatístico que favorece a quantificação e análise dos dados coletados. Recuperado de http://sphinxbrasil.com.
} 
partamento a que pertenciam no momento da escrita do texto. Embora tenha sido possível conseguir a maioria das informaçóes utilizando-se desse banco de dados, alguns autores não dispunham de um currículo Lattes, o que inviabilizou o preenchimento de alguns dados.

A seguir são apresentados, analisados e discutidos os dados obtidos por meio da enquete elaborada, conforme citado anteriormente.

\section{Resultado E Discussão}

Os dados apresentados a seguir referem-se ao Balanço Tendencial das produçóes e foram obtidos conforme descrito anteriormente. Foram elaboradas tabelas para a exposição dos resultados, organizados da seguinte forma:

1) Quem são os autores institucionais dessas narrativas?

a) Ocupação dos autores.

b) Titulação dos autores.

c) Campo de produção.

d) Vinculação Institucional.

e) Distribuição Geográfica de autoria.

2) Que sujeitos e políticas de Educação Especial essas narrativas produzem?

a) Distribuição anual dos descritores.

b) Temas das produçóes.

3) De que forma são produzidas essas narrativas?

a) Orientação metodológica.

b) Tipo de pesquisa.

\subsection{QUEM SÃo OS AUTORES INSTITUCIONAIS DESSAS NARRATIVAS?}

$\mathrm{Na}$ medida em que a produção aqui englobada é composta por textos publicados em um dos periódicos mais conceituados da área de Educação Especial - portanto encarada como expressão da produção de conhecimento nessa área - nos interessou a autoria institucional, razão pela qual este tópico se refere à ocupação, à titulação, ao campo de produçáo e ao vínculo institucional dos autores dos textos no momento de sua publicação, bem como sobre sua distribuição geográfica.

A Tabela 1 apresenta os dados sobre a ocupação dos autores no momento da publicação do artigo na RBEE: 


\begin{tabular}{|c|c|c|}
\hline OCUPAÇÃO & No & $\%$ \\
\hline Professor* & 195 & 74,1 \\
\hline Terapeuta Ocupacional & 5 & 1,9 \\
\hline Psicólogo & 6 & 2,3 \\
\hline Fonoaudiólogo & 2 & 0,8 \\
\hline Psicopedagogo & 3 & 1,2 \\
\hline Outras** & 14 & 5,3 \\
\hline Não disponível & 38 & 14,4 \\
\hline TOTAL $^{* * *}$ & 263 & 100 \\
\hline
\end{tabular}

Tabela 1. Distribuiçãa da produção pela ocupação dos autores ${ }^{10}$

Fonte: Elaboração própria.

* Desse total, 185 eram professores do Ensino Superior e dez da Educação Básica.

** Referem-se às ocupaçôes de médico, dentista, advogado, supervisor pedagógico, coordenador de escola, técnico do FNDE/ MEC, monitor, personal trainer, estudante, diretor de empresa de assessoria, instrutor de Braille e bibliotecária.

*** O total refere-se ao número de autores (263) e não ao número de textos publicados (122), tendo em vista que muitos textos foram produzidos por mais de um autor.

Verifica-se a concentração das produções no âmbito acadêmico, uma vez que, do total de publicaçóes feitas por professores, 185 estavam vinculados à academia, e os trabalhos produzidos por autores com as demais ocupaçôes foi irrisório. Essa alta concentração em autores acadêmicos é mais uma expressão localizada de que a produçáo brasileira de pesquisas no campo das práticas sociais se concretiza, fundamentalmente, no âmbito das universidades e das instituiçóes de Ensino Superior, corroborando estudo realizado por Jannuzzi (2003) referente à produção da RBEE em que aponta proveniência dos autores deste periódico fundamentalmente das universidades da área da educação.

A Tabela 2 apresenta a titulação dos autores no momento da publicação de seus artigos na Revista:

\begin{tabular}{lccc}
\hline \multicolumn{1}{c}{ TITULAÇÁO } & No & \% & Consolidado \\
\hline Doutor & 159 & 60,4 & 78,3 \\
Mestre & 47 & 17,9 & 16,0 \\
\hline Graduado & 37 & 14,1 & 5,7 \\
Graduando & 5 & 1,9 & $\mathbf{1 0 0 , 0}$ \\
\hline Não discriminado & 15 & 5,7 & $\mathbf{1 0 0 , 0}$ \\
\hline TOTAL & $\mathbf{2 6 3}$ & $\mathbf{1 0 0}$ & \\
\hline
\end{tabular}

Tabela 2. Distribuição da produção pela titulação dos autores

Fonte: Elaboração própria.

\footnotetext{
${ }^{10}$ Todas as tabelas foram elaboradas pelos autores com base nos dados dos textos selecionados para análise, referentes à produçáo da RBEE no período de 1992 a 2017, razáo pela qual a fonte não será designada nas demais tabelas. Os dados das tabelas de 1 a 5 foram complementados pela busca no currículo Lattes dos autores.
} 
Observa-se na Tabela 2 o fato de que a grande produção ficou a cargo de autores que possuem o título de doutor, com mais de $60 \%$ do total, seguidos pelos que possuem o título de mestre e depois os graduados e, por último, apenas cinco trabalhos tendo graduandos como autores.

Se desconsiderarmos, para base de cômputo, os 15 trabalhos cuja titulação não foi possível localizar, teremos um total de 48, dentre os quais 206 (78,3\%) possuem autores com titulação obtida na Pós-Graduação stricto sensu, evidenciando que a veiculação dos textos sobre a Educação Especial nesse periódico se baseia, fundamentalmente, em autores que atingiram esses dois níveis de titulação.

Os campos em que esses autores se inseriam estão dispostos na Tabela 3:

\begin{tabular}{lcc}
\hline CAMPO & No & \% \\
\hline Acadêmico & 237 & 90,1 \\
Profissional & 20 & 7,6 \\
Não disponível & 6 & 2,3 \\
\hline TOTAL & $\mathbf{2 6 3}$ & $\mathbf{1 0 0 , 0}$ \\
\hline
\end{tabular}

Tabela 3. Distribuição da autoria por campo de produção Fonte: Elaborado pelos autores.

Observa-se que quase todos os autores $(90,1 \%)$ estão inseridos no campo acadêmico, o que torna ainda mais efetiva a análise quanto à amplitude de discussão sobre a Educação Especial nas instituições de Ensino Superior, principalmente nos cursos de Pós-Graduação, uma vez que, como observado anteriormente, os autores, em sua grande maioria, são professores nesse nível de ensino.

Para avançar um pouco mais no esclarecimento a respeito das áreas que investigam a Educação Especial, a seguir é apresentada a Tabela 4 referente à vinculação institucional dos autores, inserindo-se aqueles que produzem no campo profissional e que se vinculam a uma determinada área:

\begin{tabular}{lll}
\hline VÍNCULO INSTITUCIONAL & No & \% \\
\hline Educação* & 165 & 62,7 \\
Psicologia & 56 & 21,3 \\
Saúde** $^{* *}$ & 18 & 6,8 \\
Outros** $^{* *}$ & 17 & 6,5 \\
Não disponível & 7 & 2,7 \\
\hline TOTAL & $\mathbf{2 6 3}$ & $\mathbf{1 0 0 , 0}$ \\
\hline
\end{tabular}

Tabela 4. Vinculação institucional dos autores

Fonte: Elaboração própria.

*Utilizou-se como indicador o enquadramento de professores de Graduação e Pós-Graduação em programas e/ou departamentos de Educação e Educação Especial, bem como de professores ou outros profissionais diretamente ligados à Educação Básica.

**Fazem parte dessa categoria as seguintes áreas: Terapia ocupacional, Fonoaudiologia, Fisioterapia, Enfermagem, Medicina e Atividade Física.

***Fazem parte dessa categoria os seguintes programas e/ou departamentos de IES: Engenharia de Produção; Administração; Relaçōes Públicas; Serviço Social; Ciência e Tecnologia, assim como os seguintes vínculos não ligados diretamente à IES: Psicopedagogia; Advocacia; Odontologia; Monitoria; Biblioteconomia. 
Como pode ser observado na Tabela 4, pouco menos de dois terços dos autores dos textos publicados pela RBEE estavam vinculados à área da Educação, o que evidencia que o periódico tem sido veículo privilegiado para os pesquisadores dessa área, mesmo com o critério adotado de seleção das fontes por meio de radicais (por exemplo: "DEFIC", "EXCEPC"), que poderia incluir autores de outras áreas de estudo.

Apesar de uma incidência relativamente menor, cabe ressaltar que praticamente um quinto dos artigos provém de autores da área da Psicologia - os quais, além de periódicos como este da área da Educação, possivelmente divulguem seus trabalhos em periódicos especializados de sua área.

Esse achado confronta-se com o obtido por Tezzele (2017) que, por meio do descritor "deficiência intelectual" (e com seleção de produçôes nas mesmas áreas da Tabela 4) constatou uma maior concentração de dissertaçóes e teses no campo da saúde, ou seja, o que se pode retirar desse cotejamento é que os pesquisadores dessa área, diferentemente dos de Psicologia acima referidos, divulguem seus trabalhos em periódicos próprios. ${ }^{11}$

Como apontado na Tabela 3, 7,6\% dos autores não estavam vinculados ao âmbito acadêmico, evidenciando que a produção de conhecimento, embora seja elaborada fundamentalmente nesse âmbito, permeia outros espaços profissionais. Se considerarmos que a seleção desta pesquisa privilegiou os trabalhos mais abrangentes, é possível que, em textos mais específicos essa proporção se modifique.

A seguir é apresentada a Tabela 5, referente à distribuição geográfica de autoria:

\begin{tabular}{lcc}
\hline \multicolumn{1}{c}{ REGIÁO } & No DE AUTORES & \% \\
\hline Sudeste & 168 & 64,0 \\
Sul & 47 & 17,9 \\
Nordeste & 17 & 6,5 \\
Centro-Oeste & 10 & 3,8 \\
Norte & 6 & 2,3 \\
Itália* & 2 & 0,8 \\
Portugal** & 2 & 1,0 \\
Não disponível & 11 & 4,2 \\
\hline TOTAL & $\mathbf{2 6 3}$ & $\mathbf{1 0 0 , 0}$ \\
\hline
\end{tabular}

Tabela 5. Distribuição de autoria por região

Fonte: Elaboração própria.

* Esse artigo descreve uma experiência compartilhada entre o Brasil e esse país, envolvendo 2 autores italianos e 1 autor brasileiro.

** Esses artigos envolvem autores desse país.

Fica evidente a grande concentração das produções de autores com vínculo acadêmico/profissional em instituiçóes do Sudeste do país - mais da metade - em que se concentra o

\footnotetext{
${ }^{11}$ Para cobrir a produção por meio de textos integrais no período de 1993 a 2015, o levantamento foi feito diretamente nos sites das bibliotecas das IES por ela selecionadas. Cabe, ainda, ressaltar que, pelos critérios utilizados pela CAPES na avaliaçáo dos programas de Pós-Graduação, a publicação em periódicos da própria área têm peso mais elevado.
} 
maior número de programas de Pós-Graduação, bem como os mais antigos, muitos deles com quase meio século de existência.

Além disso, cabe destacar o número de autores com vínculo institucional na região Sul (a segunda em termos de incidência) - embora inferior à primeira, é superior à soma total das demais regióes. Isso evidencia, assim como em outras áreas de pesquisa, a concentração dessa produção no eixo Sul-Sudeste, onde se encontram os Estados mais economicamente desenvolvidos do País.

Embora os dados aqui apresentados tenham caráter amostral, se comparados ao balanço efetuado por Manzini, Corrêa e Silva (2009), que apresenta dados referentes à distribuição geográfica dos autores dos textos no período de 1992 a 2008, podemos constatar bastante similaridade entre os achados: de acordo com esse estudo, em 2008, da quantidade acumulada de 287 textos publicados na RBEE, 206 textos (71,7\%) eram oriundos da região Sudeste, 49 $(17,1 \%)$ da região Sul, $15(5,2 \%)$ da região Centro-Oeste, $14(4,9 \%)$ da região Nordeste e 3 $(1,0 \%)$ da região Norte.

Por outro lado, os achados do estudo elaborado por Ferreira e Bueno (2011), referente às produçóes expostas nas Reunióes Anuais da Associação Nacional de Pós-Graduação e Pesquisa em Educação (ANPEd), dentro do GT 15- Educação Especial, no período de 2002 a 2010, embora evidenciem tendência semelhante de distribuição geográfica de suas autorias, apresenta uma distinção marcante, qual seja a da praticamente igualdade entre autores da região Sudeste e os da região Sul: 54 autores da região Sudeste e 53 da região Sul.

\subsection{Que SUJeItos E POlíticas de EduCAÇÃo EsPeCIAL ESSAS NARRATIVAS PRODUZEM?}

Conforme a perspectiva apresentada por Bourdieu (2004) - de que o objeto de pesquisa é construído, conquistado - este tópico apresenta, em primeiro lugar, os dados referentes aos termos utilizados para designação da população envolvida, colhidos por meio dos descritores $^{12}$ utilizados nas produçóes dos textos publicados na Revista Brasileira de Educação Especial e sua distribuição por período, tendo em vista que a distribuição desses termos em períodos de tempo diferentes pode expressar modificaçóes conceituais e, em segundo lugar, os dados relativos aos temas mais recorrentes nas produçóes.

Os achados referentes à distribuição anual dos termos utilizados para designar a população envolvida nos textos estão dispostos na Tabela 6. Previamente, cumpre destacar que a periodicidade de publicação da RBEE passou por modificações no decorrer desse período, fato relevante para proceder à análise da tabela, visto que a produção aumentou significativamente a partir do ano 2000. Cabe reiterar que até o ano 2000, a publicação era anual, passando a ser semestral de 2001 a 2003, quadrimestral de 2004 a 2011 e trimestral a partir de 2012.

\footnotetext{
12 Utilizou-se o radical “EXCEPC” para buscar todas as palavras que se referiam à Excepcionalidade e a Excepcional; "DEFIC” para as que se referiam à Deficiente, Deficiência; “TRANST" para as que se referiam a Transtorno; "NEE” para buscar palavras que se referiam a Necessidades Educativas Especiais; Necessidades Educacionais Especiais; "NE” às Necessidades Especiais.
} 


\begin{tabular}{lcccccccccc}
\hline \multirow{2}{*}{ PERÍODO } & \multicolumn{2}{c}{ DEFIC } & \multicolumn{2}{c}{ NEE } & \multicolumn{2}{c}{ NE } & \multicolumn{2}{c}{ TRANST } & \multicolumn{2}{c}{ EXCEPC } \\
& Quant & $\begin{array}{c}\text { No } \\
\text { Índice }\end{array}$ & Quant & $\begin{array}{c}\text { No } \\
\text { Indice }\end{array}$ & Quant & $\begin{array}{c}\text { No } \\
\text { Índice }\end{array}$ & Quant & $\begin{array}{c}\text { No } \\
\text { Indice }\end{array}$ & Quant & $\begin{array}{c}\text { No } \\
\text { Índice }\end{array}$ \\
\hline$<$ de 1995 & 5 & 1,0 & 2 & 1.0 & 4 & 1,0 & 0 & - & 3 & 1,0 \\
$1995-1999$ & 7 & 1,4 & 2 & 1,0 & 3 & 0,75 & 0 & - & 3 & 1,0 \\
$2000-2004$ & 18 & 3,6 & 12 & 6,0 & 11 & 2,75 & 0 & - & 2 & 0.75 \\
$2005-2009$ & 28 & 5,6 & 22 & 11,0 & 22 & 5,5 & 4 & 1,0 & 3 & 1,0 \\
$2010-2017$ & 52 & 10,4 & 32 & 16,0 & 26 & 6,5 & 22 & 4,5 & 3 & 1,0 \\
\hline TOTAL & $\mathbf{1 1 0}$ & - & $\mathbf{7 0}$ & - & $\mathbf{6 6}$ & - & $\mathbf{2 6}$ & - & $\mathbf{1 4}$ & - \\
\hline
\end{tabular}

Tabela 6. Distribuição anual dos descritores utilizados para designação da população (1992/2017)

Fonte: Elaboração própria.

Observa-se que os termos designativos pelo radical "DEFIC" foram os mais utilizados nas produçôes publicadas na RBEE, seguidos pelos termos designados pelas siglas "NEE" ou "NE". Mesmo assim, embora em números reais, a maior incidência total alcançada fosse dos termos designados pelo radical "DEFIC", em temos proporcionais a designação "NEE" apresentou o crescimento mais expressivo: 16 vezes maior do que o ano base, contra 10,4 vezes do primeiro. Se a esse último termo "NEE" acrescentarmos os designados pela sigla "NE", teremos um total de 136 utilizaçóes, superando o anterior também em números reais.

$\mathrm{O}$ incremento da utilização dessas siglas pode ser imputado à influência que a Declaração de Salamanca (1994) exerceu não somente sobre as políticas de Educação Especial como também sobre a produção acadêmica. No entanto, quando se procura designar parte dessa população, aqueles que apresentam prejuízos cognitivos, auditivos, visuais e físicos, a utilização de termos designados pelo radical "DEFIC" parece ser obrigatória.

Além disso, o incremento expressivo da utilização desse radical a partir de 2000 parece evidenciar que, após o impacto inicial do termo divulgado pela Declaraçáo, neste novo século, ele voltou a ser utilizado de forma expressiva, dadas as críticas que autores como Meletti e Bueno (2011) e Jesus e Oliveira (2014), entre outros, estabeleceram sobre o uso generalizado de necessidades especiais, sem uma caracterização mais precisa da população envolvida em diferentes investigaçôes.

Além disso, Bueno (2011, p. 12) considera que a substituição do termo "excepcional" para designar o alunado da Educação Especial, designados pelo radical "EXCEPC" por necessidades educativas especiais, apesar de ter por objetivo a inserção dos problemas de escolarização dos alunos da Educação Especial como uma expressão localizada dos mecanismos de seletividade escolar, náo consegue diminuir nem a pejoratividade do antigo termo, nem favorece a busca de maior precisão para delimitaçáo da populaçáo a ser por ela incorporada, pois, na sua utilização prática, não consegue diminuir "a função de encobrir os determinantes socio-históricos na caracterização da anormalidade" (Bueno, 2011, p. 26).

Já o crescimento dos termos designados pela sigla "NEE" expressa sua adoção a partir de Salamanca, mas, ao mesmo tempo, pode-se constatar a permanência dos termos designados 
pela sigla "NE", o que mostra que a designação oficial nem sempre é seguida imediatamente na produção acadêmica.

Os dois outros termos designados pelos radicais "TRANST" e "EXCEPC" apresentam uma incidência bem menor, embora os termos designados pelo radical "EXCEPC" tenham sido utilizados constantemente no decorrer das produçóes no período, mas com baixa incidência anual (três por ano), com exceção do período de 2000 a 2004.

A utilização dos termos designados pelo radical "TRANST", no entanto, parece refletir situação muito distinta, na medida em que ele passou a ser utilizado somente a partir de 2005, com um aumento significativo a partir de 2010. Esse aumento parece expressar um novo momento na conceituação da população atendida pela Educação Especial, com forte influência do campo da medicina por meio da utilização cada vez mais intensa do termo, "transtorno", tal como se pode constatar pela publicação do DSM-V (American Psychiatric Association [APA], 2013). ${ }^{13}$

Ainda referente ao "o que" produzem os autores que publicam na Revista Brasileira de Educação Especial, foi elaborada a Tabela 7 a seguir, que se refere aos temas das produçóes.

\begin{tabular}{lccc}
\hline \multicolumn{1}{c}{ TEMAS } & No DE TEXTOS & $\%$ & CONSOLIDADO \\
\hline Prática pedagógica & 29 & 23,7 & 38,5 \\
Formaçáo de professores & 18 & 14,8 & \\
\hline Identidade da Educaçáo Especial & 18 & 14,8 & 41,0 \\
Política & 17 & 13,9 & \\
Pesquisas em Educação Especial & 15 & 12,3 & 20,5 \\
\hline Família & 7 & 5,7 & \\
Profissionalização e mercado de trabalho & 9 & 7,4 & \\
Diagnóstico e/ou avaliação & 5 & 4,1 & \\
Gênero e sexualidade & 3 & 2,5 & \\
Violência & 1 & 0,8 & $\mathbf{1 0 0 , 0}$ \\
\hline TOTAL & $\mathbf{1 2 2}$ & $\mathbf{1 0 0 , 0}$ & \\
\hline
\end{tabular}

Tabela 7. Temas das produções na RBEE Fonte: Elaboraçáo própria.

Observa-se nesta tabela, composta por dois blocos, que os temas mais incidentes constantes do primeiro bloco se referem à educação escolar, constituída por dois conjuntos de temas que analisam a formação e a prática docente, totalizando 38,5\% das produçóes, e por um conjunto de temas que se voltam a análises da natureza e função da Educação Especial, analisando sua identidade, com 14,8\% das produçóes, seguido por trabalhos que analisam a questão política, perfazendo um total de $13,9 \%$ e, finalmente, um tema numericamente expressivo $(12,3 \%)$, com foco sobre a produção de pesquisa no campo.

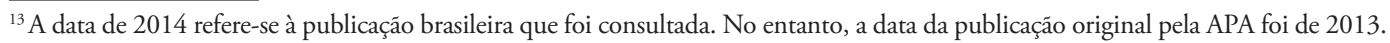


Verifica-se, portanto, que a temática geral que move o interesse dos pesquisadores refere-se à educação escolar da população abrangida pela Educação Especial, com incidência muito próxima da encontrada por Bueno (2014), no balanço que realizou sobre as dissertaçóes e teses sobre Educação Especial defendidas no período de 1987 a 2009, corroborando também resultados encontrados por Manzini (2003) em balanço realizado sobre artigos publicados na RBEE, indicando que os temas educação e ensino eram os mais frequentes naquele período analisado.

No segundo bloco, com incidência bem menos expressiva, situam-se textos que se voltam mais a aspectos referentes aos fatores relacionados à inserção social, perfazendo um total de 20,5\% das produçóes. Nesse caso, cabe ressaltar que, assim como se constatou no tópico do vínculo institucional, o critério adotado de seleção das fontes por meio de radicais (por exemplo: "DEFIC", "EXCEPC”), pode estar influenciando essa distribuição.

Apresentados e analisados os dados sobre os autores institucionais e do que tratam esses artigos, cabe verificar como essas narrativas são produzidas, assunto do próximo tópico.

\subsection{DE QUE FORMA SÃo PRODUZIDAS ESSAS NARRATIVAS?}

A RBEE é composta, atualmente, por seçóes que passaram a integrá-la a partir de 2002 e que se mantêm até os dias atuais - entre elas, as seçôes Ensaios e Relatos de Pesquisa, de cujos textos foram selecionados para análise. No período anterior (1992 a 2001), como não havia essa designação, foram selecionados somente aqueles definidos pela própria Revista como Artigos. ${ }^{14}$

Referente à organização dos textos na Revista, constatou-se que, de 1992 até 2001, a quantidade publicada era de oito a dez artigos por número; de 2002 até 2007 (Volume 13 No 2), foram publicados entre sete e oito relatos de pesquisas e um ensaio por número; a partir de 2007 (Volume 13 No 3), passou-se a publicar entre sete e dez relatos de pesquisas e entre um a três ensaios. Todavia, o número de publicações não ultrapassou 12 textos, o que indica que esse periódico segue uma organização referente ao limite de textos, que se mantém. Na Tabela 8 a seguir, é apresentada a distribuição dessa produção por gênero textual.

\begin{tabular}{lll}
\hline \multicolumn{1}{c}{ GÊNERO TEXTUAL } & No DE TEXTOS & \multicolumn{1}{c}{$\%$} \\
\hline Relato de pesquisa & 80 & 65,6 \\
Artigo & 24 & 19,7 \\
Ensaio & 18 & 14,7 \\
\hline \multirow{2}{*}{ TOTAL } & $\mathbf{1 2 2}$ & $\mathbf{1 0 0 , 0}$ \\
\hline
\end{tabular}

Tabela 8. Gênero do texto ${ }^{15}$

Fonte: Elaboraçáo própria.

Conforme a Tabela 8, é possível verificar que o gênero textual mais divulgado na RBEE é o relato de pesquisa, tendo em vista que a própria organização da Revista destina

${ }^{14}$ Além dos números regulares, foram incluídos na seleção os textos designados "Artigos", aqueles que compõem o Volume 17, Número Especial (2011).

${ }^{15}$ As designaçôes quanto ao gênero textual são aquelas apresentadas pela própria Revista. 
maior espaço a esse tipo de texto, como apontado anteriormente. Os ensaios, embora tenham continuidade no decorrer do período, são encontrados em menor número - no máximo três em alguns números -, e os artigos não têm um fluxo contínuo, como citado anteriormente.

Nota-se, portanto, que, embora a designação dada pela própria Revista se diferencie a partir de 2001, os textos que a compóem têm características que perduram no decorrer do tempo, tendo os relatos de pesquisa uma maior representatividade desde o início, o que indica o esforço na constituição de um campo de conhecimento.

De acordo com Paviani (2009), embora se possa reconhecer que um ensaio possui características que o distinguem de um relato de pesquisa - por exemplo: não apresentar uma estética definida, maior liberdade para defender uma ideia, opinião, expor críticas e reflexóes sobre determinado assunto, não demandar apoio empírico nem documental ou outros recursos para sustentar as ideias expostas -, observou-se que muitos textos designados "ensaios" apresentam as mesmas características dos relatos de pesquisa, apoiando-se ora em pesquisa documental, ora em estudos de caso, além de não se diferenciarem dos relatos de pesquisa em termos de estrutura: introdução, desenvolvimento e consideraçôes finais.

No que se refere à orientação metodológica da pesquisa, a Tabela 9 a seguir apresenta os seguintes resultados:

\begin{tabular}{lcc}
\hline ORIENTAÇÃO METODOLÓGICA & QUANT & \% \\
\hline Qualitativa & 85 & 69,70 \\
Quantitativo-Qualitativa & 36 & 29,50 \\
Quantitativa & 1 & 0,80 \\
\hline TOTAL & $\mathbf{1 2 2}$ & $\mathbf{1 0 0 , 0}$ \\
\hline
\end{tabular}

Tabela 9. Distribuição das produções por orientação metodológica Fonte: Elaboraçáo própria.

Nessa tabela, observa-se a elevada incidência de produçôes com orientação metodológica qualitativa - 69,7\% dos textos. As pesquisas que se utilizaram de dados quantitativos totalizaram menos da metade em relação às primeiras. Contudo, ocorre aqui uma diferença importante em relação a outros balanços, como o de Ferreira e Bueno (2011, p. 64), sobre os trabalhos apresentados no GT-15 Educação Especial, da ANPEd, em que a incidência de trabalhos seguindo essa orientação foi de apenas 2,1\%, contra $97,0 \%$ de artigos que se enquadraram como pesquisa qualitativa. Da mesma forma, o capítulo de Bueno (2014, p. 233), sobre dissertaçóes e teses defendidas no período de 1987 a 2009, mostrou incidência bastante semelhante à anterior: apenas $0,6 \%$ de pesquisas quantitativo-qualitativas contra 96,1\% de trabalhos com orientação qualitativa. Esse incremento percentual parece refletir uma diversificação metodológica bastante positiva, em período de tempo relativamente curto.

A existência de apenas um trabalho com a orientação metodológica quantitativa reitera os achados desses trabalhos indicados: no de Ferreira e Bueno (2011), apenas três entre 132 trabalhos $(2,3 \%)$ seguiram essa orientação metodológica, enquanto que, no de Bueno (2014), esse percentual foi ainda mais baixo (seis entre 1.068 produçóes, ou seja, 0,06\%). 
A última tabela apresenta a distribuição dos artigos pelo tipo de pesquisa utilizado.

\begin{tabular}{lcc}
\hline \multicolumn{1}{c}{ TIPO DE PESQUISA } & No DE TEXTOS & $\%$ \\
\hline Documental & 54 & 44,3 \\
De campo & 46 & 37,7 \\
De campo/ Documental & 4 & 3,3 \\
Outro & 18 & 14,7 \\
\hline TOTAL & $\mathbf{1 2 2}$ & $\mathbf{1 0 0 , 0}$ \\
\hline
\end{tabular}

Tabela 10. Distribuição das produçóes por tipo de pesquisa ${ }^{16}$ Fonte: Elaboração própria.

Esses dados mostram que a maioria esmagadora das produções foi fruto de pesquisas que utilizaram documentos ou de técnicas de pesquisa de campo para sua realização, perfazendo $82 \%$ do total.

Se excluirmos os dezoito artigos que não foram fruto de pesquisas, esse percentual cresce ainda mais, com 100 trabalhos dentre 104 utilizando um dos dois tipos de pesquisa, com apenas quatro utilizando ambos os tipos. Cabe ressaltar que a distribuição entre esses dois tipos se diferencia muito dos resultados obtidos em balanços anteriores, pois, no de Ferreira e Bueno (2011, p. 165), essa proporção foi de $64,3 \%$ de pesquisas de campo contra $28,1 \%$ de pesquisas documentais.

Assim, os achados referentes à orientação metodológica e tipo de pesquisa parecem mostrar que a veiculação da produção de conhecimento da área em periódico avaliado por pares (o que, em tese, implicaria maior rigor na sua seleção) apresenta uma diversificação de procedimentos e instrumentos de pesquisa mais evidente do que em trabalhos apresentados em eventos científicos, assim como nas teses e nas dissertaçóes, objetos dos balanços com os quais foram feitos cotejamentos.

\section{Consideraçóes finais}

Por meio desse balanço tendencial envolvendo 263 autores que produziram 122 textos publicados na Revista Brasileira de Educação Especial em 25 anos de trajetória, procuramos evidenciar as principais tendências de trabalhos veiculados pela RBEE, selecionados por abordarem o tema da Educação Especial de forma mais abrangente, envolvendo a autoria institucional, o tema/sujeitos sobre os quais se debruçaram, assim como os procedimentos metodológicos utilizados nas pesquisas que redundaram nesses trabalhos.

Cabe destacar que a pesquisa reiterou os achados de outros balanços, como o efetuado por Bueno (2014), de concentração de autores oriundos da Pós-Graduação, com 70\%

\footnotetext{
${ }^{16}$ Para a elaboração desta tabela, foram utilizados os seguintes critérios - Abordagem documental: refere-se aos textos que realizam a análise por meio de fontes documentais (tabelas estatísticas; cartas; pareceres; fotografias; atas; relatórios; notas; diários; projetos de leis; discursos; informativos; depoimentos orais e escritos; correspondências); De campo: análises por meio de observações; entrevistas; questionários; intervenção e pesquisa-ação; De campo/documental: análises empreendidas por meio das duas abordagens em conjunto; Outro: textos que apresentam ideias, opiniōes, críticas e reflexôes sem apoio de material empírico ou documental.
} 
exercendo a docência no Ensino Superior e, como era de se esperar, a maior parte dos autores atuando na área da educação, já que é um periódico especializado nessa área, com grande concentração de pesquisadores da região Sudeste do País.

$\mathrm{O}$ que parece ser o achado mais interessante refere-se à terminologia utilizada para designar o alunado da Educação Especial: embora com variação temporal na incidência, como, por exemplo, o crescimento dos termos necessidades educativas especiais e necessidades especiais, a partir do ano 2000, eles são utilizados em todo o período.

A manutenção do termo deficiência, durante todo o período, e com curva de crescimento semelhante à dos termos anteriores, revelou que não resta qualquer dúvida de que esse alunado é parte integrante da Educação Especial, enquanto os outros termos parecem possuir vida mais efêmera, tal como ocorreu com o termo "excepcional" e, mais modernamente, com a expressão "necessidades especiais".

Em síntese, tal como indica Bourdieu (1983), a produção de conhecimento no campo da Educação Especial (assim como de todas as práticas sociais que se constituem como objetos de pesquisa) é influenciada pelo campo político, assim como este recebe influência das investigaçóes levadas a efeito.

Embora haja essa influência recíproca, não se pode esperar que elas sejam incorporadas por ambos os campos de forma imediata, pois cada um desses campos que compóem o espaço social possui autonomia relativa, na medida em que, enquanto no campo acadêmico científico a disputa se trava em torno da "autoridade científica", o campo político é arena de disputa das ações expressa pela enunciação e a imposição dos "bons" princípios de visão e de divisão: a "política é uma luta em prol de ideias, mas um tipo de ideias absolutamente particular, a saber, as ideias-força, ideias que dão força ao funcionar como força de mobilização" (Bourdieu, 2011, p. 203). Assim, vale a pena reiterar que a imbricação entre esses dois campos merece ser continuamente investigada, não para se construir uma perspectiva idealista de que a política absorva de imediato todas as contribuiçôes da produção acadêmica, mas para se desvelar as reais relaçóes que se estabelecem entre esses dois campos.

Por fim, cabe no fechamento deste artigo, retomar dois elementos centrais sobre os quais procuramos nos pautar em relação à produção de conhecimento da área, veiculadas por meio da RBEE: a diversidade de temas, focos e processos de construçáo metodológica; e as disputas teórico-práticas expressas por essa diversidade.

Com relação ao primeiro elemento, a diversidade constatada não deve ser encarada, tal como argumenta Canário (1996, p. 134), como problema ou fragilidade teórica mas, ao contrário, revela que ela coloca

em evidência o carácter pouco fecundo e até artificial de algumas falsas querelas que, frequentemente, atravessam o debate metodológico. A tendência para raciocinar a partir do estabelecimento de dicotomias entre o qualitativo e o quantitativo, entre o experimental e o naturalista, não corresponde, seguramente, ao modo mais adequado e produtivo de equacionar o debate metodológico. Parece-me, no entanto, importante esclarecer que os modos de investigação e as técnicas de recolha e tratamento da informação decorrem, e são parte constitutiva e integrante, do processo de construção do objeto de estudo. A metodologia, entendida num sentido amplo e não redutível a técnicas ou preceitos normativos, atravessa a globalidade do processo de inves- 
tigação. Esta constitui um todo, que não pode ser pensado como uma simples sequência linear de etapas predeterminadas.

No que se refere à segunda, na esteira da referência teórica que utilizamos para a análise aqui encetada (Bourdieu, 1983), a divulgação pela RBEE de artigos sobre a Educação Especial, como expressão da prática social da produção de conhecimentos oriundos de pesquisa, envolve disputas teórico-práticas que, como toda e qualquer prática social, embora possa abarcar subjetivismos e vaidades pessoais e de grupos, é, antes de mais nada, a busca incessante e contínua que os pesquisadores da área efetuam da "autoridade científica", que constitui o móvel essencial de nossas atuaçôes no campo acadêmico. E isso, com certeza, não é pouco...

\section{REFERÊNCIAS}

American Psychiatric Association (2013). Diagnostic and Statistical Manual of Mental Disorders (DSM5) (5a ed.). Washington: APA.

Bourdieu, P. (1983). O campo científico. In R. Ortiz (Org.), Pierre Bourdieu: Sociologia (P. Montero, \& A. Auzmendi, Trad., pp. 122-155). São Paulo: Ática.

Bourdieu, P. (1991). Langage et Pouvoir Symbolique. Cambridge, Grande-Bretagne: Polity Press.

Bourdieu, P. (2004). Coisas ditas (C. R. da Silveira, \& D. M. Pegorim, Trad.). São Paulo: Brasiliense. 2004.

Bourdieu, P. (2011). O campo político. Revista Brasileira de Ciência Política, 5, 193-216.

Bueno, J. G. S. (2011). Educação especial brasileira: Questôes conceituais e de atualidade. São Paulo: EDUC.

Bueno, J. G. S. (2014). A pesquisa brasileira sobre educação especial: Balanço tendencial das dissertaçôes e teses brasileiras (1987-2009). In J. G. S. Bueno, K. Munakata, \& D. F. Chiozzini (Org.), A escola como objeto de estudo: Escola, desigualdades, diversidades (pp. 211-244). Araraquara, SP: Junqueira \& Marin.

Canário, R. (1996). Os estudos sobre a escola: Problemas e perspectivas. In J. Barroso (Org.), O estudo da escola (pp. 121-149). Porto: Porto Editora.

Declaração de Salamanca: Sobre princípios, políticas e práticas nas áreas das necessidades educativas especiais (1994). Recuperado em 29 de junho de 2018 de http://portal.mec.gov.br/seesp/arquivos/pdf/ salamanca.pdf

Ferreira, J. R., \& Bueno, J. G. S. (2011). Os 20 anos do GT educação Especial: Gênese, trajetória e consolidação. Revista Brasileira de Educação Especial, 17(n. espec.), 143-169.

Jannuzzi, G. S. de M. (2003). Algumas reflexóes sobre a Revista Brasileira de Educação Especial. Revista Brasileira de Educação Especial, 9(1), 7-12.

Jesus, J. L. B., \& Oliveira, M. R. F. de. (2014). Os alunos com necessidades educacionais especiais e a inserçấo no mercado de trabalho: Que possibilidade temos? Anais da Jornada de Didática, Londrina, PR, Brasil, 3. Recuperado em 29 de junho de 2018 de https://goo.gl/t469cv

Manzini, E. J. (2003). Análise de artigos da Revista Brasileira de Educação Especial (1992-2002). Revista Brasileira de Educação Especial, 9(1), 13-24.

Manzini, E. J., Corrêa, P. M., \& Silva, M. O. da. (2009). Disseminação de conhecimento em educação especial no Brasil: As contribuições da ABPEE. Revista Brasileira de Educação Especial, 15(2), 181-196. 
Meletti, S. M. F., \& Bueno, J. G. S. (2011). O impacto das políticas públicas de escolarização de alunos com deficiência: Uma análise dos indicadores sociais no Brasil. Linhas críticas, 33, 367-383.

Paviani, J. (2009). O ensaio como gênero textual. Anais do Seminário Internacional de Estudos de Gêneros Textuais: O ensino em foco, Caxias do Sul, RS, Brasil, 4. Recuperado em 3 de novembro de 2017 de http://www.escrevendoofuturo.org.br/arquivo/65/o-ensaio-como-genero-textual. pdf

Tezzele, P. C. M. (2017). A produção acadêmica sobre deficiência intelectual: Um balanço das teses defendidas entre 1993 e 2015 (Tese de Doutorado). Pontifícia Universidade Católica de São Paulo, São Paulo, SP, Brasil.

Recebido em: 19/03/2018

Reformulado em: 16/05/2018

Aceito em: 11/06/2018 
BUENO, J.G.S. \& SOUZA, S.B. 